\title{
Usefulness of arterial blood gas estimations during exercise in patients with chronic heart failure
}

\author{
A L Clark, A J S Coats
}

\begin{abstract}
Background-Coexisting cardiorespiratory disease may contribute in individual cases to the increased ventilatory response to exercise in patients with chronic heart failure.

Objective-To characterise further the arterial blood gas response to exercise and to explore the possible uses of blood gas sampling in clinical practice in patients with chronic heart failure.

Methods-37 patients with a primary diagnosis of chronic heart failure (age (range) 59 (45-80); left ventricular ejection fraction $24 \cdot 5 \%(4 \%-44 \%)$ ) underwent exercise testing with arterial blood gas analysis during exercise.

Results-In 34 patients there was a small fall in arterial carbon dioxide tension from a mean (SEM) of $4.9(0.1) \mathrm{kPa}$ at rest to $4.6(0 \cdot 1) \mathrm{kPa}$ at peak exercise $(p<$ $0 \cdot 001)$. There was no significant change in arterial oxygen tension. During the recovery period arterial oxygen tension rose from $13.3(0.3) \mathrm{kPa}$ at peak exercise to $14.8(0.3) \mathrm{kPa}$ three minutes into recovery $(p<0.001)$. Arterial carbon dioxide tension was unchanged. In the remaining three patients there was considerable arterial hypoxaemia on exercise, from $10.4 \mathrm{kPa}$ at rest to $7.7 \mathrm{kPa}$ at peak exercise. All of these patients had an alternative diagnosis (patent foramen ovale with right to left shunt during exercise, pulmonary embolic disease, and clinically unsuspected obstructive airways disease).

Conclusion-Patients with a presumptive diagnosis of chronic heart failure should undergo exercise testing with arterial blood gas analysis. Arterial hypoxaemia on exercise is rare in stable chronic heart failure. If hypoxia on exercise is detected, an alternative diagnosis should be sought.
\end{abstract}

\section{(Br Heart f 1994;71:528-530)}

epartment of Cardiac Medicine, National Heart and Lung Institute, London

A L Clark

A J S Coats

Correspondence to: Dr A J S Coats, Departmen of Cardiac Medicine, National Heart and Lung Institute, Dovehouse Street, London SW3 6LY.

Accepted for publication

3 November 1993

Patients with chronic heart failure complain of breathlessness and fatigue on exercise. The breathlessness is accompanied by an objective increase in ventilation at a given work load, ${ }^{1-3}$ and an increase in ventilation at any given value of carbon dioxide production. ${ }^{4}$ Patients with chronic heart failure maintain nearly normal concentrations of arterial blood gases aemia or hypercapnia develop may have important implications for therapeutic options in chronic heart failure, as it may justify the use of supplementary oxygen. ${ }^{7}$ We wished to study further the response in arterial blood gas tensions in patients with chronic heart failure to determine the possible clinical role of exercise assessment with oximetry or blood gas measurement in patients with heart failure.

\section{Patients and methods}

Thirty-seven patients with a primary diagnosis of exertional dyspnoea due to chronic heart failure underwent symptom limited treadmill exercise tests. All patients were known to have left ventricular dysfunction and were not limited by either angina or claudication. None of the patients was known to have lung disease. A standard Bruce protocol was used with the addition of a stage 0 (three minutes exercise at $1 \mathrm{mile} / \mathrm{h}$ with a $5 \%$ gradient) at the start of exercise. Patients were encouraged to exercise to exhaustion.

Before exercise, an arterial catheter (Leader cath, Vygon) was inserted under local anaesthesia into the non-dominant radial artery after first ensuring that a patent ulnar artery was present. The artery was flushed periodically with a $10 \mu / \mathrm{ml}$ solution of heparin. Resting measurements were taken before the start of exercise after a five minute period of rest. Arterial samples for analysis were taken at rest, at peak exercise, and three minutes into the recovery period. Arterial blood gas samples were analysed for partial pressures of oxygen and carbon dioxide, and $\mathrm{pH}$, with a blood gas analyser (CIBA Corning) after two point calibration before each run.

\section{STATISTICS}

Within subject comparisons were made with paired Student's $t$ tests, with corrections for multiple comparisons by Scheffe's procedure. Between group analysis was made with the unpaired Student's $t$ test. Corrected $\mathrm{p}$ values $<0.05$ were taken to be significant. In the text, results are quoted as means (SD).

The study was approved by the ethics during exercise. ${ }^{56}$ Whether arterial hypox-
Results

There were no complications arising from the exercise tests or the arterial punctures. 
Table 1 Patient characteristics $(n=37)$

\begin{tabular}{ll}
\hline Age (yr, range) & $59 \cdot 1(45-80)$ \\
Sex (M, F) & 35,2 \\
Diagnosis: & 22 \\
IHD & 12 \\
DCM & $245 \%(4 \%-44 \%)$ \\
EF (\% range) & \\
NYHA grade: & 9 \\
I & 6 \\
II & 13 \\
III & 6 \\
IV & 6 \\
\hline
\end{tabular}

IHD, ischaemic heart disease; DCM, dilated cardiomyopathy, $\mathrm{EF}$, left ventricular ejection fraction by gated radionucleide scanning; NYHA, New York Heart Association functional class of heart failure.

In 34 patients, arterial oxygen was unchanged during exercise. At rest, the arterial oxygen tension was $12.9(0.3) \mathrm{kPa}$ (saturation $97 \cdot 0 \%(1 \cdot 1 \%)$ ) and at peak exercise it was $13.3(0.3) \mathrm{kPa}$ (saturation $98.7 \%(1.0 \%)$ ). Table 1 shows patient characteristics for this group. In three patients arterial oxygen fell.

In the 34 patients with unchanged oxygen tensions $\left(\mathrm{PaO}_{2}\right)$ at peak exercise, $\mathrm{PaO}_{2}$ rose during the recovery period, from $13.3(0.3)$ to $14.8(0.3) \mathrm{kPa}(\mathrm{p}<0.001$ table 2$)$. In the same 34 patients, arterial carbon dioxide tension $\left(\mathrm{PaCO}_{2}\right)$ fell from a resting value of $4.9(0.1)$ to $4.6(0.1) \mathrm{kPa}$ at peak exercise $(p<0.001)$ with no further change into the recovery period. Arterial $\mathrm{pH}$ fell during exercise from $7.43(0.006)$ to $7.40(0.007)$ $(\mathrm{p}<0.001)$, and fell further during recovery to $7.38(0.009)(p<0.001)$. Average exercise time was 526 (175) seconds. The three patients with substantial hypoxaemia on exercise were investigated further. All three had been referred with a diagnosis of exertional dyspnoea secondary to heart failure.

\section{PATIENT 1}

A 53 year old man presented initially (overseas) in 1988 with an acute inferior myocardial infarction. In the period immediately after infarction, he had episodes of complete heart block with ventricular standstill. His illness was complicated by recurrent bouts of ventricular tachycardia. On returning to the United Kingdom, he underwent coronary arteriography and electrophysiological testing. This showed normal coronary arteries, with inferior left ventricular hypokinesia. He had an inducible ventricular tachycardia, for which he received disopyramide and subsequently amiodarone.

Over the next three years he became gradually more short of breath on exertion. Echocardiography showed a worsened left ventricular function, with dilatation of both ventricles. Multiple gated radionuclide scanning of the heart showed a left ventricular

Table 2 Arterial blood gas data (mean (SEM), $n=37$ )

\begin{tabular}{llcl}
\hline Data & Rest & Peak exercise & Recovery \\
\hline $\mathrm{PaO}_{2}(\mathrm{kPa})$ & $12 \cdot 9(0 \cdot 3)$ & $13 \cdot 3(0 \cdot 3)$ & $14 \cdot 8(0 \cdot 3)^{\star \star}$ \\
$\mathrm{PaCO}_{2}(\mathrm{kPa})$ & $4 \cdot 9(0 \cdot 1)$ & $4 \cdot 6(0 \cdot 1)^{\star}$ & $4 \cdot 6(0 \cdot 1)$ \\
Arterial pH & $7 \cdot 43(0.006)$ & $7 \cdot 40(0.007)^{\star \star}$ & $7 \cdot 38(0 \cdot 009)^{\star}$
\end{tabular}

$\overline{\mathrm{PaO}_{2}}$, is arterial oxygen tension; $\mathrm{PaCO}_{2}$, arterial carbon dioxide

${ }^{\star} \mathrm{p}<0.005 ;{ }^{\star \star} \mathrm{p}<0.001$ compared with the column to the left ejection fraction of $33 \%$ with discoordinate contraction. Computerised tomographic scans of the lungs were normal, with no sign of interstitial lung disease.

He undertook a symptom limited maximal treadmill exercise test. At rest, his $\mathrm{PaO}_{2}$ was $7 \cdot 85 \mathrm{kPa}$ (saturation $90.5 \%$ ), and $\mathrm{PaCO}_{2} 2.95$ $\mathrm{kPa}$. Within 60 seconds of exercise, his $\mathrm{PaO}_{2}$ had fallen to $5 \cdot 64 \mathrm{kPa}$ (saturation $78 \cdot 1 \%$ ) and his $\mathrm{PaCO}_{2}$ to $2.5 \mathrm{kPa}$. He was able to exercise for a total of 340 seconds. Ventilation perfusion scans and formal pulmonary function tests were normal. Echocardiography with contrast injection and an exercise test with pressure monitoring of right ventricular and atrial pressures showed a patent foramen ovale. During cardiac catheterisation, a right to left shunt during exercise was shown through the foramen ovale.

His patent foramen ovale was too large to be occluded by a USCI clam shell or Rashkind device and his right ventricular function was considered too poor for surgical closure. He was accepted for cardiac transplantation, but he deteriorated rapidly and died before an organ became available. No post mortem report was available.

\section{PATIENT 2}

A 58 year old man presented with gradual onset of shortness of breath for the preceding six months. He had normally been fit, jogging five miles daily. At the time of presentation, he was no longer able to run. He was a nonsmoker and had no relevant personal or family history. Although his physical examination was normal, a chest $x$ ray film showed an enlarged heart. An echocardiogram indicated left ventricular dysfunction with a mildly dilated left ventricle. $\mathrm{He}$ was provisionally diagnosed to have dilated cardiomyopathy.

He underwent exercise tests with arterial blood sampling for measurement of gas tensions. $\mathrm{His} \mathrm{PaO}_{2}$ at rest was $13 \cdot 1 \mathrm{kPa}$ (saturation $97 \cdot 8 \%$ ), but fell to $8.7 \mathrm{kPa}$ (saturation $91.5 \%$ ) at peak exercise. $\mathrm{His} \mathrm{PaCO}_{2}$ was 4.8 $\mathrm{kPa}$ at rest and $5.0 \mathrm{kPa}$ at peak exercise. He exercised for 940 seconds. In view of the fall in arterial oxygen tension, he underwent contrast echocardiography and ventilation-perfusion scanning. This showed decreased perfusion to the apex of the right lung with less well defined areas of decreased perfusion in the left lung. Ventilation was normal. Contrast echocardiography showed no evidence of an intracardiac shunt. $\mathrm{He}$ was treated for pulmonary embolic disease.

He had broken his left leg before the onset of his breathlessness, and underwent a prolonged period of inactivity after the injury. Six months after treatment, he is asymptomatic and off all medication. Left ventricular ejection fraction is $55 \%$ by radionuclide scanning.

\section{PATIENT 3}

A 73 year old man with a long history of rheumatic heart disease presented with a history of increasing shortness of breath on exercise over the previous 12 months. He had had a mitral valvotomy for mitral stenosis and an 
aortic valve xenograph for aortic stenosis in 1981.

A chest $x$ ray film showed cardiac enlargement and pulmonary congestion. An echocardiogram showed normal left ventricular dimensions with mild mitral stenosis and aortic stenosis with a peak aortic outflow velocity of 2.7 m.s. $^{-1}$. There was tricuspid regurgitation that indicated a pulmonary artery pressure of about $60 \mathrm{~mm} \mathrm{Hg}$. Cardiac catheterisation showed a pulmonary artery pressure of $55 / 34 \mathrm{~mm} \mathrm{Hg}$ and mean pulmonary capillary wedge pressure of $26 \mathrm{~mm} \mathrm{Hg}$. The end diastolic gradient across the mitral valve was $4 \mathrm{~mm} \mathrm{Hg}$ and a peak to peak aortic gradient was $10-20 \mathrm{~mm} \mathrm{Hg}$. There was mild left ventricular dysfunction. His shortness of breath was assumed to be due to the combination of valvar lesions.

During exercise tests, his $\mathrm{PaO}_{2}$ fell from $10.25 \mathrm{kPa}$ (saturation $95.4 \%$ ) at rest to 8.72 $\mathrm{kPa}$ (saturation $92 \cdot 1 \%$ ) at peak exercise, and his $\mathrm{PaCO}_{2}$ rose from $7.04 \mathrm{kPa}$ to $7.78 \mathrm{kPa}$. As a result, he underwent formal lung function tests. Total exercise time was 240 seconds. His forced expiratory volume in one second $\left(\mathrm{FEV}_{1}\right)$ was $750 \mathrm{ml}$ (33\% of predicted) and his forced vital capacity (FVC), $1400 \mathrm{ml}$ ( $47 \%$ of predicted), giving an $\mathrm{FEV}_{1} / \mathrm{FVC}$ ratio of $53 \%$. His total lung capacity (TLC) was $5850 \mathrm{ml}$ ( $102 \%$ of predicted). Analysis of his flow volume loop confirmed his severe expiratory airflow limitation. He had been a smoker for 25 years having given up 10 years before presentation.

\section{Discussion}

Although patients with chronic heart failure become breathless with exercise and have an increased ventilatory response, arterial blood gas tensions are usually said to be maintained near to normal, ${ }^{56}$ although some people have suggested a reduced arterial saturation in some patients with chronic heart failure and have suggested a possible beneficial response to increased inspired concentrations of oxygen. ${ }^{7}$ Other investigators, however, have found evidence for an increase in arterial oxygen content in patients with chronic heart failure. ${ }^{8}$

In this study, we have confirmed that arterial oxygen and carbon dioxide tensions remain near normal in patients with chronic heart failure, as does arterial oxygen saturation. As others have found, ${ }^{910}$ we have shown a small fall in arterial carbon dioxide at peak exercise, and a notable rise in oxygen during the recovery phase in these patients. This finding has important clinical and theoretical implications. If the arterial gases sensed by the peripheral chemoreceptors are normal on exercise, or even better than at rest, then the cause of the sustained increase in ventilatory response to exercise is not clear. The common explanation of an increase in dead space venti- lation does not explain how this is sensed against a background of normal blood gases on exercise. Other explanations for the increased response are needed. ${ }^{11}$

The clinical implications are that patients with chronic heart failure do not develop arterial hypoxaemia or desaturation. If hypoxaemia is found, further investigation is indicated. Unsuspected lung disease, intracardiac shunts, and pulmonary embolic disease are possible causes of hypoxaemia, which should be sought. An exercise test with arterial blood gas sampling carries little risk of damage at the arterial puncture site; however, most district general hospitals will have the capacity to measure continuous oxygen saturation by pulse oximetry. Arterial blood gas sampling has the added advantage of measuring arterial carbon dioxide tension and can thus show whether carbon dioxide retention or hyperventilation is occurring. Nevertheless, pulse oximetry would have shown the desaturation in the three patients reported here.

The clinical course of heart failure is varied. We suggest that as part of the assessment of chronic heart failure at diagnosis, patients should undergo exercise tests with arterial blood gas sampling or oximetry where the accuracy of the pulse oximeter has been established. Furthermore, it may be useful in investigating patients with unexplained deterioration. The finding of any desaturation or hypoxaemia during exercise suggests that an alternative diagnosis should be sought.

Supported in part by a grant from the Clinical Research Committee of the Royal Brompton National Heart and Lung Cospital. ALC is a Robert Luff Fellow and AJSC is the Viscount Royston and British Heart Foundation is the Lecturer.

1 Higginbotham MB, Morris KG, Conn EH, Coleman RE, Cobb FR. Determinants of variable exercise performance among patients with severe left ventricular dysfunction. Am 7 Cardiol 1983;51:52-60.

2 Rubin SA, Brown HV. Ventilation and gas exchange during exercise in severe chronic heart failure. Am Rev Respir Dis 1984;129(suppl):S63-4.

3 Sullivan MJ, Higginbotham MB, Cobb FR. Increased exercise ventilation in patients with chronic heart failure: intact ventilatory control despite haemodynamic and pulmonary abnormalities. Circulation 1988;77:552-9.

4 Buller NP, Poole-Wilson PA. Mechanism of the increased ventilatory response to exercise in patients with chronic ventilatory response to exercise in patie
heart failure. Br Heart $\mathcal{7}$ 1990;63:281-3.

5 Rubin SA, Brown HV, Swan HJC. Arterial oxygenation and arterial oxygen transport in chronic myocardial failure at rest, during exercise and after hydralazine treatment. Circulation 1982;66:143-8.

6 Franciosa JA, Leddy CL, Wilen M, Schwartz DE. Relation between haemodynamic and ventilatory responses in determining exercise capacity in severe congestive heart failure. Am $\mathcal{A}$ Cardiol 1984;53:127-34

7 Moore DP, Weston AR, Hughes JMB, Oakley CM, Cleland JGF. Effects of increased inspired oxygen concentrations on exercise performance in chronic heart failure. Lancet 1992;339:850-3

8 Herrlin B, Sylvén C. Increased arterial oxygen contentan important compensatory mechanism in chronic moderate heart failure. Cardiovasc Res 1991;25:384-90.

9 Rajfer SA, Nemanich JW, Shurman AJ, Rossen JD. Metabolic responses to exercise in patients with heart failure. Circulation 1987;76(suppl VI):V146-53.

10 Moore DP, Gilligan D, Oakley CM. Hypocapnia during exercise testing in dilated cardiomyopathy and hyperexercise testing in dilated cardiomyopathy and hypertrophic cardiomyopathy: objective assessm
ratory gas analysis. Br Heart $\mathcal{f} 1989 ; 61: 435$.

11 ratory gas analysis. Br Heart $\mathcal{f} 1989,61.435$. in chronic heart failure. Eur Heart f 1992;13:1698-708. 